\title{
ЗАГАЛЬНЕ МОВ0ЗНАВСТВО
}

УДК 811.162

DOI https://doi.org/10.32838/2710-4656/2021.6-2/01

Алиева Н. С.

Бакинский государственный университет

\section{СЛОЖНЫЕ СЛОВА В ГОНЧАРНОЙ ЛЕКСИКЕ АЗЕРБАЙДЖАНСКОГО ЯЗЫКА}

Певна частина гончарної лексики азербайджанської мови складається зі слів із складною структурою. Слова зі складною структурою становлять невелику частину лексикону гончарного мистецтва і не відрізняються різноманітністю з погляду способу їх утворення. Дослідження показують, що слова зі сфери гончарного мистецтва зі складною структурою мають кілька структурних типів. Серед них переважає другий тип визначальних словосполучень, утворених іменниками з першим компонентом у невизначеному давальному відмінку, другий компонент - ие структурно-семантичні типи дієприкметників із суфіксом -ап2 та дієприслівників із суфіксом -та2. Відомо, що більшість слів професійного мистецтва зі складною структурою формується на основі структурно-смислового типу, представленого другим типом словосполучення, тобто дієприкметником. Зазначимо, що історія складних слів у цій моделі не така вже давня. У мові давньотюркських писемних пам'яток є складні назви, і більшість зразків складається з другого типу визначальних словосполучень. Перший компонент гончарних слів у моделі дієслівного словосполучення у знахідному відмінку зазвичай виражсається іменниками. Перший компонент гончарних слів у моделі відмінювання дієслів також виражається іменниками. Другий же компонент, як зазначалося вище, виражається дієприкметниками з суфіксом -ап2 та дієприслівниками з суфіксом -та2. Складні гончарні слова, утворені поєднанням двох іменників у зв'язиі, представлені лише одним словом. Слід зазначити, щзо навіть після завершення утворення складних слів вони зазнають різних фонетичних та семантичних змін, внаслідок чого втрачають особливості слів своєї групи і набувають нових якостей. Гончарні слова з іншими структурами (поєднання прикметника з іменником, чисельника з іменником тощо) рідко зустрічаються і не можуть вважатися провідною структурою в изому лексичному шарі.

Ключові слова: гончарне мистечттво, азербайджанська мова, ремісництво, словниковий склад, складні слова.

Введение. Процесс формирования сложных слов в немалой степени связан с развитием ремесел, в том числе гончарного ремесла. Подобное словообразование широко распространено в тюркских языках. Сложные слова в области керамики, возникшие в результате сочетания существительного с числительным, представлены обычно как одно слово. Хотя слова из гончарной сферы в этой модели кажутся несколько искусственными, они сформировались в рамках грамматических правил азербайджанского языка.

Лексические и грамматические особенности слов из гончарной лексики. Определенная часть гончарной лексики азербайджанского языка состоит из слов со сложной структурой. Изна- чально следует отметить, что слова со сложной структурой составляют небольшую часть лексикона гончарного дела и не являются красочными с точки зрения способа образования. С учетом всего этого слова со сложной структурой в гончарной лексике азербайджанского языка можно классифицировать следующим образом:

1. Гончарные слова, образованные в модели второго типа определения: çarxbaşı - «часть над гончарным кругом», həlimqabl-«гончарный сосуд для питья отвара плова», qәndqabl - «фарфоровая сахарница», quyubaşı - «глиняная крышка для прикрытия печи в земле», охиси - «металлический наконечник стрелы на гончарном круге», olxovdaşı - «глиняный горшок для намазывания 
теста» (ADDL, с. 381), pitidopusu - «гончарный сосуд для приготовления пити».

Г. Аскеров, изучая профессиональные слова азербайджанского языка, отмечает, что большинство профессиональных слов со сложной структурой формируется на основе вышеуказанного структурно-семантического типа, и пишет, что этот тип сложных слов имеет ряд особенностей. Средства выражения компонентов сложных слов, которые появляются в этом варианте, очень ограничены. Их компоненты в основном выражаются именами. Кроме того, характер грамматических взаимоотношений между компонентами этого типа составного слова отличается от характера взаимоотношений у других составных слов [2, с. 292]. Следует отметить, что такое мнение Г. Аскерова абсолютно верно. В разных областях лексики владения азербайджанским языком по модели второго типа словосочетания сформировались десятки слов. Например, itgolu - «мастерок, используемый в кузнечном деле», gargaburnu - «плоскогубцы, используемые для сгибания железа», qolaxçası - «украшение запястья, руки в ювелирных изделиях», gücüaltı - «деревянный брус длиной 50-70 см, используемый в ковроткачестве», ayıqulă̆ı, quşarmudu - «растения с сильными дубильными свойствами, используемые в кожевенном производстве», ocaqbaşl - «небольшой ковер, сотканный для того, чтобы класть его на верхнюю часть очага», dəvəqulağ - «многолетнее растение, используемое при окрашивании для получения желтого цвета». Однако в лексиконе гончарного дела есть несколько сложных слов, которые встречаются в модели определения второго типа. На основе этой структурной модели мы выделили шесть слов.

Также возникают разногласия относительно сложных слов, образованных в модели второго типа определения, в современном азербайджанском языке. Рассматривая взгляды и мнения по этому поводу, М. Адилов отмечает: «Можно выделить некоторые признаки, свидетельствующие о завершении процесса грамматически законченного образования сложных слов, который проявляется в виде определения второго типа. Мы пока говорим о завершении лишь процесса окончательного формирования. Вместе с тем процесс образования сложных слов из составных слов все время продолжается. Хотя некоторые словосочетания и имеют определенное значение, их грамматическое формирование только начинается. Одни из них находятся примерно на полпути. Другие уже завершили свой путь и грамматиче- ски полностью сформированы. Суффикс второго компонента в этих полностью сформированных словах больше не слышится как суффикс, а скорее воспринимается как последняя гласная обычных слов» [1, с. 152-153].

Второй тип определения в лексике гончарного дела - это сложные слова, образованные в модели словосочетаний, которые также находятся на разных стадиях грамматического формирования. Например, рассмотрим использование слов qəndqabr (сахарница) и pitidopusu (кувшин для варки обеда) с разными грамматическими суффиксами. Когда вы добавляете суффикс -lar, который является количественным суффиксом, к слову $q \partial n d q a b l$, оно становится во множественном числе: qandqabllar. Слово pitidopusu встречается в форме pitidopular (множественное число). Это означает, что слово qәndqabl уже полностью сформировано, суффикс принадлежности в этом слове не может выполнять никаких грамматических функций и ведет себя как последняя гласная в слове. Слово pitidopusu еще не полностью сформировано грамматически, и в этом слове проявляются особенности обычного словосочетания. Вот почему в этом слове количественный суффикс используется до, а не после суффикса принадлежности.

Как известно, слово ayaqqabı (обувь) - одно из самых распространенных в азербайджанском языке. Сопоставление слов qəndqabl и halimqabl (блюдо для рисового отвара) в лексиконе гончарного дела с этим словом позволяет составить точное представление об уровне грамматической сформированности таких слов. Сходство слов, которые выступают вторым компонентом в образовании всех трех лексических единиц, также делает это сравнение интересным. Все три слова во множественном числе имеют количественный суффикс: ayaqqabilar, qəndqabılar, holimqabilar. Когда мы добавляем к этим словам словообразовательный суффикс $-d a k i^{2}$ для образования от этих существительных определения, мы сталкиваемся с другой картиной. Слово ayaqqabı ведет себя как полностью сформированное составное слово, то есть оно принимает суффикс $-d a k i^{2}$ как простое слово, оканчивающееся на гласную: ayaqqabıdakı. Слово qәndqabı может использоваться с суффиксом - $d a k l^{2}$ как в формах qəndqabıdakl, так и в формах qəndqabindakl, и это не влияет на значение словоформ. Слово həlimqabı нельзя использовать в форме holimqabıdakı. Его можно использовать только в виде halimqabındakı. Другими словами, суффикс принадлежности в слове holimqabı имеет грамматическое значение, а не окаменевшую 
форму. Исходя из этого, можно сказать, что слово ayaqqabı грамматически уже полностью сформировано, слово qәndqabl находится в завершающей стадии формирования, а слово halimqabı еще, по словам М. Адилова, находится на полпути.

История составных слов во втором типе определения не так уж и стара. Хотя Н. Худиев и считает, что в языке древнетюркских письменных памятников существуют сложные существительные, все приводимые им примеры состоят из второго типа определенных словосочетаний [3, с. 88-89]. Такой же подход мы находим в исследовании А. Мамедова. Он также считает такие словосочетания, как Ötükən ylş, boz at, kisi oğll, составными существительными [4, с. 181-183]. Примечательно мнение А. Танриверди о том, что составные существительные, образованные структурносемантическим сочетанием двух и более слов, редко встречаются в азербайджанском литературном языке до XVIII в. [5, с. 226]. Он приводит примеры таких слов, как әmiraxurbaşı, şahinçibaşı, Qabangüci, Dəmirgüci, quzuqulağl, bəglarbəgi, в качестве архаичных для современного азербайджанского литературного языка и образованных на основе развития составных слов: onbaşı, yüzbaşl, minbaşı, yasovulbaşı. Кстати, первый компонент второго типа определенного артикля (слово в случае неопределенного винительного падежа) означает общность, абстракцию, первый компонент третьего типа определенного слова (определенный винительный падеж) выражает конкретность, определенность. В этом смысле сложное существительное может быть преобразовано во второй тип определительного словосочетания, но не в третий тип определительного словосочетания. Это находит свое подтверждение в том, что слово отличается по уровню абстрагирования, по сравнению со словосочетанием [5, с. 227]. Все это наглядно показывает, что сложные слова этой модели не случайно попали в лексикон гончарного дела, а возникли в результате длительного исторического развития.

2. Гончарные слова, образованные по образцу глаголов действия. Первый компонент гончарных слов в этой модели обычно выражается существительными. С точки зрения выражения второго компонента существует два типа гончарных слов такого рода:

a) первый компонент составного слова выражается существительными, а второй компонент выражается причастиями с суффиксом $-a n^{2}$. Сравним: aşsüzən (сито, кухонная утварь из керамики или железа), çilovsüzən (сито для сцеживания чего- либо), kirəmitbişirən (рабочий на керамзитном производстве) (ADIL, II, c. 710), külçəbasan (гончарный инструмент с различными орнаментами для украшения хлебобулочных изделий), suçiləyən (лейка), susəpәn (большая лейка с небольшими отверстиями в верхней части трубы для полива, опрыскивания), tüstüçəkən (дымоход для регулирования горения древесины и температуры в печи), yelçəkən (конструкция вентилятора для регулирования горения древесины и температуры в печи).

Любая грамматическая связь между составляющими такого сложного слова возможна только с исторической точки зрения. Сильной грамматической связи между составляющими вновь образованного слова нет. Приведенные выше примеры показывают, что отглагольные прилагательные, которые здесь выступают вторым компонентом, сочетаются со словом, которое стоит перед ними, и выражают объект, образуя слово, которое при этом выражает новое понятие. Известно, что деепричастия в определенных случаях управляют существительным. С такой точки зрения, можно сказать, что грамматическая связь между этими примерами - это связь управления. Однако следует учитывать, что связь между компонентами не рабочая, а в застывшем состоянии. Другими словами, связь между компонентами составного слова в некоторой степени соответствует связи между компонентами словосочетания. Образование сложных слов в результате сочетания глаголов и предметов - явление типологическое и наблюдается в ряде языков мира;

б) первый компонент составного слова выражается существительными, а второй компонент выражается отглагольными существительными с суффиксом -ma $a^{2}$. Сравните: dəmalma (охлаждение глиняной посуды внутри печи), dodaqçıхаrma (вытягивание верхней части горлышка керамики для получения формы горшка с длинным горлышком), içaçma (расширение и углубление среднего отверстия горшка на гончарном круге), qulpqoyma (приделывание ручки на предмете, изготавливаемом гончарным способом), palçıqtutma (изготовление смеси путем смешивания глины с водой), susəpтә (поливание водой смеси из замешанной глины), tüstüvermə (окуривание дымом гончарных изделий до их запекания для того, чтобы они не потрескались). М. Адилов пишет о втором компоненте составных глаголов с суффиксом - $m a^{2}$, что прилагательные, образованные с помощью этих суффиксов, сочетаются со словами перед ними, чтобы образовать новое значимое существительное и прилагательное. Новые сложные слова имеют прямое и косвенное значения. 
Например, maşınqayırma, yerdəyişmə, yeniyetmə, alsixmalar, adqoyma (соответственно, машиностроение, смена места, отрочество, рукопожатие, наименование и т. д.) $[1$, с. 170$]$.

3. Сложные гончарные слова, образованные в результате сочетания двух связанных существительных. Эта модель представлена в лексиконе гончарного дела всего одним словом - sacayaq (глиняная подставка, помещенная под железный круг для выпекания хлеба, для его удержания). Г. Аскеров относит это слово к группе сложных слов, состоящих из простых существительных, оба компонента которых образованы на основе сопоставительной связи: «Фактически мы условно включили в эту группу слово sacayaq. Это слово, которое сейчас является сложным, исторически образовалось в виде sacayağı, т. е. в виде слога II типа, но впоследствии утратило свою форму. Фактически в компонентах, составивших это слово, налицо не сопоставительная, а управляющая связь, наряду с которой просматривается и сочетательная связь. При дальнейшем развитии азербайджанского языка последний звук - - в слове sacayağl, т. е. суффикс в функции принадлежности, был утерян, и в результате слово потеряло свою внутреннюю форму. В слове sacayaq сочетание компонентов не мотивировано. В данном случае слово sacayaq может быть отнесено только к этой группе» [2, с. 280-281].

Мы также согласны с данным мнением Г. Аскерова. Следует отметить, что даже после образования и завершения сложных слов они претерпевают различные фонетические и семантические изменения, в результате чего теряют характер слов, принадлежащих их группе, и приобретают новое качество. Например, слова dilbir, albir, sözbir (единый язык, единство, единое слово), которые, на первый взгляд, напоминают первый тип определенных словосочетаний, исторически образовались в форме dilibir, alibir, sözübir, т. е. в виде модели именного словосочетания, не входящего в состав определительного словосочетания. Мы встречаем похожие процессы в хакасском языке. Сравните: Moynax (собачья кличка), Strtax (кличка коровы). Эти слова образовались в комбинированной модели именных словосочетаний, которая не вошла в определение типа тоупи ах (белая шея) и sirtı ax (белая спинка), а позже стала составным именем существительным [11, с. 124]. Итак, со временем, по мере образования новых слов, появляются новые формы, новые модели словообразования. Не исключено, что последний звук - - в слове sacayağ с фонотактикой тюркских языков, в том числе азербайджанского. Как известно, в тюркских языках многосложные слова используются нечасто, а сокращение количества слогов в словах - обычное языковое явление. О. Йылдыз, изучающий сложные слова современного турецкого языка, указывает, что формирование некоторых сложных слов еще не завершено, и потому члены составной структуры этих слов в значительной степени сохраняют свое значение. В подобных сложных словах или вообще не происходит никаких фонетических событий, к примеру, это слова ağaçkakan (дятел), buzdolabı (холодильник), büyükelçi (посол), bakımevi (амбулатория), или же они образуются посредством увеличения согласных или снижения числа гласных и слогов: ne ise > neyse, biri birine > birbirine, şiş kebabl > şişkebap, top kapısı > Topkapl, kadı köyü > Kadıköy (соответственно, в общем; в общем, друг другу; друг другу, мясо на шомполе; мясо на шомполе, пушечный вход; пушечный вход, местоположение) и др. [8, с. 234].

Следует отметить, что в написании таких слов в турецком языке, как и в азербайджанском, существуют некоторые различия [7, с. 693-706].

4. Сложные гончарные слова, образованные путем сочетания простого прилагательного и простого существительного. Эта модель представлена одним словом в лексиконе гончарного дела tayqulp (гончарный сосуд для приготовления пити (мясное блюдо), в некоторых местах его называют piti barnisi). Ф. Зейналов показывает, что создание сложных слов этим методом широко распространено в тюркских языках [6, с. 95]. Исследователь шорского языка А. Есипова также отмечает, что в этом языке словосочетания, связанные атрибутивной связью, впоследствии превратились в сложное слово [9, с. 44]. Говоря об этом типе составных слов, М. Сарсенбаева пишет, что во многих случаях невозможно определить происхождение составного слова, т. е. нельзя сказать, что оно возникло в результате лексикализации словосочетаний или в результате произвольных сочетаний компонентов [10, с. 34].

5. Сложные гончарные слова, образовавшиеся в результате сближения числительного с производным прилагательным. Эта модель представлена в лексиконе гончарного дела словом dördayaqlı (тип треножника). Не только в лексике гончарного дела, но и в лексиконе профессий в целом есть несколько слов с такой структурой. Сравните: biralli (медная чаша для воды с одной ручкой), təkəlli (медная чаша для воды также с одной ручкой), üçayaqlı (треножник, железная подставка, предмет домашнего обихода), ikiqulplu (двояковыпуклый узор средней 
каймы ворсовых ковров) [2, с. 283]. Хотя сложные слова, относящиеся к глиняному производству, в этой модели кажутся несколько искусственными, они возникли в рамках грамматических правил азербайджанского языка.

Изучение лексических единиц со сложной структурой в гончарной лексике азербайджанского языка позволяет сделать следующие выводы:

1. Слова со сложной структурой составляют небольшую часть лексики керамического производства и не отличаются структурным и семантическим разнообразием.

2. Слова о керамическом производстве и его продукции со сложной структурой в основном наблюдаются в нескольких структурных типах, в том числе возникших в модели второго типа определения, т. е. лексических единицах, образованных лексикализацией второго типа определения, так как первый компонент является существительным в неопределенном винительном падеже. Во втором компоненте преобладают лексические единицы, то есть причастия, выраженные суффиксом - $a n^{2}$ и отглагольными именами с суффиксом - $m a^{2}$.

3. Слова керамической принадлежности с иной структурой (прилагательное с существительным, числительное с существительным и т. д.) являются редкими и не могут считаться ведущей структурой в этом лексическом слое.

\section{Список литературы:}

1. Adilov M. Osərləri, I cild. Bak1 : Elm və təhsil, 2010. 308 s.

2. Osgərov H. Azərbaycan dilinin maddi mədəniyyət leksikası. Bak1: Bakı Universiteti nəşriyyatı, 2006. 447 s.

3. Xudiyev N. Qədim türk yazılı abidələrinin dili. Bakı : Elm və təhsil, 2015. $596 \mathrm{~s}$.

4. Məmmədov A. Tarixi yaddaş milli dil güzgüsündə (Qədim türk abidələrinin leksikası və Azərbaycan dili). Bak1 : ADMIU-nun nəşriyyat1, 2015. $292 \mathrm{~s}$.

5. Tanrıverdi Ә. Azərbaycan dilinin tarixi qrammatikası. Bak1 : Elm və təhsil, 2010. $458 \mathrm{~s}$.

6. Zeynalov F. Türk dillərinin müqayisəli qrammatikası, I hissə (Fonetika, leksika, morfologiya). Bakı : MBM nəşriyyatı, 2008.354 s.

7. Koç R. Türkçede Birleşik Kelimelerin Yazımı İle İlgili Tartışmalar ve Çözüm Önerileri. Kastamonu Eğitim Dergisi. Cilt 15. Say1 2. Ekim 2007. S. 693-706.

8. Yıldız O. Birleşik Kelimelerde Görülen Fonetik Hadiseler, Terimleri, Tanımları ve Örneklerinin tasnifi Üzerine. Turkish Studies. İternational Periodical For the Languages, Literature and History of Turkish or Turkic. 2015. Vol. 10/8, Spring. P. 231-252.

9. Есипова А. Теоретические проблемы словообразования в тюркских языках (на материале шорского языка) : автореф. дисс. ... д-ра филол. наук. Москва, 2011. 51 с.

10. Серсенбаева М. О семантическом аспекте словообразования в казахском языкознании. Филологические науки. 2011. С. 34-35.

11. Тараканова И. Словообразование имен существительных в хакасском языке (в сопоставительном аспекте). Абакан : Хакасское книжное издательство, 2008. 174 с.

\section{Лексические источники:}

ADDL. Azərbaycan dilinin dialektoloji lüğəti, Bak1 : Şərq-Qərb, 2007. $568 \mathrm{s.}$

ADILL. Azərbaycan dilinin izahlı lüğəti. Dörd cilddə, Bakı : Şərq-Qərb, 2006. I c. 744 s.; II c. 792 s.; III c., 672 s.; IV c. 712 s.

\section{Aliyeva N. S. DIFFICULT WORDS IN POTTERY VOCABULARY OF THE AZERBAIJAN LANGUAGE}

A certain part of the pottery vocabulary of the Azerbaijani language consists of words with a complex structure. Words with a complex structure make up a small part of the vocabulary of pottery and do not differ in terms of the way they are formed. Research shows that pottery words with complex structures have several structural types. Among them, the second type of attributive phrases prevails, formed by nouns with the first component in the indefinite dative case, the second component is the structural-semantic types of participles with suffixes $-a n^{2}$ and gerunds with suffixes $-m a^{2}$. It is known that most of the words of professional art with a complex structure are formed on the basis of the structural-semantic type, represented by the second type of phrase, that is, the participle. Note that the history of compound words in this model is not that old. In the language of ancient Türkic written monuments, there are complex names, and most of the samples consist of the second type of attributive phrases. The first component of pottery words in the accusative verbal model is usually expressed by nouns. The first component of pottery words in the verb conjugation model is usually expressed by nouns. The second component, as mentioned above, is expressed by participles with the-an ${ }^{2}$ suffix, and gerunds with the -ma ${ }^{2}$ suffix. Complicated pottery words, formed by combining two nouns in a bundle, are represented by only one word. It should be noted that even after the completion of the formation of complex words, they undergo various phonetic and semantic changes, as a result of which they lose the features of the words of their group, and acquire a new quality. Pottery words with other structures (a combination of an adjective with a noun, a numeral with a noun, etc.) are rarely encountered and cannot be considered the leading structure in this lexical layer.

Key words: pottery, Azerbaijani language, handicraft, vocabulary, compound words. 